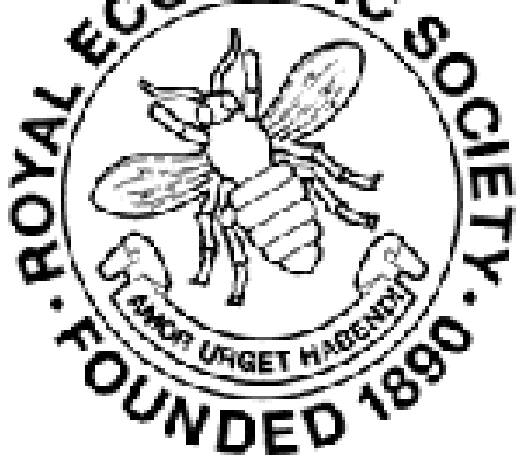

\title{
WILEY
}

A New Standard of Value

Author(s): Walter Bagehot

Source: The Economic Journal, Vol. 2, No. 7 (Sep., 1892), pp. 472-477

Published by: Wiley on behalf of the Royal Economic Society

Stable URL: http://www.jstor.org/stable/2955973

Accessed: 26-06-2016 02:11 UTC

Your use of the JSTOR archive indicates your acceptance of the Terms \& Conditions of Use, available at

http://about.jstor.org/terms

JSTOR is a not-for-profit service that helps scholars, researchers, and students discover, use, and build upon a wide range of content in a trusted digital archive. We use information technology and tools to increase productivity and facilitate new forms of scholarship. For more information about JSTOR, please contact support@jstor.org.

Royal Economic Society, Wiley are collaborating with JSTOR to digitize, preserve and extend access to The Economic Journal 


\section{A NEW STANDARD OF VALUE '}

Professor Jevons, of Manchester-so well known in the economical and statistical world by his researches on coal-has written an excellent treatise on 'Money and the Mechanism of Exchange,' which we strongly recommend to our readers. It is extremely clear, brief without being dry, and contains a good deal of very interesting information. And we may add that it is written in a style of scientific modesty rare in currency books. Mr. Jevons is perpetually aware that the subject abounds in questions of nicety and difficulty, on which he is quite ready to admit that he may be wrong. It would be a happy thing if persons far less competent than Mr. Jevons to write on the subject, but who incessantly do so, could be brought to that admission.

On one point, however, we are at issue with Mr. Jevons: he has far more hope from economical science than we have. $\mathrm{He}$ thinks that it can point out to mankind a far better theoretical standard of value than gold or silver, and believes that, though it is encumbered with some difficulties, probably the new plan would on the whole, when we got used to it, work better than our present one. But for ourselves we much fear that political economy has no such boon to confer on mankind, and that we must adhere to one or other of the precious metals as a standard of value, like our forefathers. Mr. Jevons shall explain his fundamental idea in his own words.

'The question,' he says, 'thus arises whether the progress of economical and statistical science might not enable us to devise some better standard of value. We have seen (pp. 136-143) that the so-called double standard system of money spreads the fluctuations of supply and demand of gold and silver over a larger area, and maintains both metals more unchanged in value than they would otherwise be. Can we not

1 Reprinted from The Economist for November 20, 1875. 
conceive a multiple legal tender, which would be still less liable to variation? We estimate the value of one hundred pounds by the quantities of corn, beef, potatoes, coal, timber, iron, tea, coffee, beer, and other principal commodities, which it will purchase from time to time. Might we not invent a legal tender note which should be convertible, not into any one single commodity, but into an aggregate of small quantities of various commodities, the quantity and quality of each being rigorously defined? Thus a hundred pound note would give the owners a right to demand one quarter of good wheat, one ton of ordinary merchant bar iron, one hundred pounds weight of middling cotton, twenty pounds of sugar, five pounds of tea, and other articles sufficient to make up the value. All these commodities will, of course, fluctuate in their relative values, but if the holder of the note loses upon some, he will in all probability gain upon others, so that on the average his note will remain steady in purchasing power. Indeed, as the articles into which it is convertible are those needed for continual consumption, the purchasing power of the note must remain steady compared with that of gold or silver, which metals are employed only for a few special purposes.'

And he goes on to explain that of course this kind of currency could not, in practice, be used, as no one wishes to have all these miscellaneous things, or could pass them away if he had them. But Mr. Jevons does not think this objection conclusive: he borrows from a nearly forgotten writer of fifty years ago-named 'Lowe'-an expedient which he thinks meets the difficulties satisfactorily.

'Mr. Lowe,' we are told, 'treats, in a very enlightened manner, of the fluctuations in the value of money, and proceeds to propound a scheme, probably invented by him, for giving a steady value to money contracts. He proposes that persons should be appointed to collect authentic information concerning the prices at which the staple articles of household consumption were sold. In regard to corn and sugar, authoritative returns were then, and have ever since been, published in the London Gazette, and there seemed to be no difficulty in extending a like system to other articles. Having regard to the comparative quantities of commodities consumed in a household, he would then frame a table of reference, showing in what degree a money contract must be varied so as to make the purchasing power uniform. In principle, the scheme seems to be perfectly sound; but Lowe did not attempt to work out the practical details, and his plan involves needless difficulties. A very similiar scheme was independently proposed, about eleven years later, by Mr. G. Poulett Scrope, the well-known writer on geology and political economy. In a very able but now forgotten pamphlet, called 'An Examination of the Bank Charter Question, with an Inquiry into the Nature of a Just Standard of Value" (London,

No. 7.-VOL. II 
1833), Mr. Scrope suggests (p. 26) that a Standard might be formed by taking an average of the mass of commodities which, even if not employed as the legal standard, might serve to determine and correct the variations of the legal standard. The scheme was also described in Mr. Scrope's interesting book on the Principles of Political Economy, published in the same year (p. 406), and in the second edition of the same book, called Political Economy for Plain People, issued two years ago (p. 308). The late Mr. G. R. Porter, without referring to previous writers, gave the same scheme in 1838 in the first edition of his wellknown treatise on The Progress of the Nation (Sections III. and IV., page 235). He added a table showing the average fluctuations of fifty commodities monthly during the years 1833 to 1837 . Such schemes for a tabular or average standard of value appear to be perfectly sound and highly valuable in a theoretical point of view, and the principal difficulties are not of a serious character. To carry Lowe's and Scrope's plans into effect, a permanent government commission would have to be created, and endowed with a kind of judicial power. The officers of the department would collect the current prices of commodities in all the principal markets of the kingdom, and, by a well-defined system of calculations, would compute from these data the average variations in the purchasing power of gold. The decisions of this commission would be published monthly, and payments would be adjusted in accordance with them. Thus, suppose that a debt of one hundred pounds was incurred upon the 1st of July, 1875, and was to be paid back on the 1st July, 1878; if the commission had decided in June, 1878, that the value of gold had fallen in the ratio of 106 to 100 in the intervening years, then the creditor would claim an increase of 6 per cent. in the nominal amount of the debt. At first the use of this national tabular standard might be permissive, so that it could be enforced only where the parties to the contract had inserted a clause to that effect in their contract. After the practicability and utility of the plan had become sufficiently demonstrated, it might be made compulsory, in the sense that every money debt of, say, more than three months' standing, would be varied according to the tabular standard, in the absence of an express provision to the contrary.' And Mr. Jevons rather boldly says that 'the objections to this scheme are not considerable.'

But we confess they seem to us so many, and so important, that we hardly know where to begin.

First,-it is wholly unfit for a nation which has a foreign trade. A foreigner wants payment in a medium which he can use in his own country, and he wants to be precisely sure how much of that medium he will receive. Since the civil war the United States have been excessively inconvenienced by the want of such a medium. A bill. drawn on New York for 1,000 dollars would be paid in greenbacks, but greenbacks are of no use out of 
America; to be of use elsewhere they must be changed into gold or silver, and the rate at which they can be so changed is uncertain. And the 'tabular standard' is radically faulty in the very same way. No one could tell what a draft, say for $£ 1,000$ on London, would fetch; it might be $£ 1,060$, or anything else. There would always be an uncertain percentage. Since the Franco-German war London has become the exchange centre for Europe far more than before, because the infinitesimally small premium on gold as compared with Bank of France notes introduced an uncertain element. But all the business so obtained we should lose, and much more, under the 'tabular standard.' London would be unfit for exchange business of any sort; there would always be a far larger inscrutable element which would drive all such business away. And, more generally, every importer of goods into England would then have to consider what would be his possible loss by fluctuations in the currencywhich, as America has found to her cost, is the greatest discouragement and check to trade.

Secondly,-It would make banking impossible. A banker would never know what he owed. At periodical intervals the Commissioners would say that he owed less or more. And in the case of each debt he must do a separate sum, since money might have changed in 'purchasing power,' as respects the 'tabular' commodities, more or less according to the time at which each debt was contracted; it might be more in six months, and less in three months, or just the contrary. Then, again, on his unoccupied cash-say on the $£ 10,000,000$ reserve in the Bank of England-the loss or gain by fluctuations would be prodigious ; and the gain would be no compensation for the loss, since it would turn the trade into a kind of gambling, by introducing an incalculable element into it. And it would be quite impossible to explain the matter to the ordinary and poorer customers. Farmer A would always say he was cheated if he did not get as much for his debt as farmer B, though if the two debts were of different dates such would be the necessary effect of the plan, and though the banker fully expounded it. No doubt too poor people would be cheated, not of course by bankers, but by designing people of every sort; an element incomprehensible by the people is fatal to a popular currency, for it is essential to one that the people should understand it-should know when it was well used, and see that it was not misused.

Probably our readers will think these objections enough, but we have not finished; for thirdly,-it would be necessary to 
preserve most elaborate standards of the various articles which constitute the standard, else we should, in so fine a matter, make the most serious errors, for almost every article varies in quality as well as in quantity, and its value depends nearly as much on one as on the other. But as most articles are perishable you could not preserve a standard of them. Nor could you define the quality in Act of Parliament, so that it could be tested. Every one who has studied our former sugar duties knows how difficult it was to give even a rude definition of the sort of sugar intended. And if the law were to try to fix the standard quality of 'fifty' different articles, it would fail. No draughtsman could put the quality of beef, or pork, or tea, into an. Act of Parliament. Mr. Jevons refers to the 'Gazette average of corn,' as if it helped his plan. But there is no better instance to point this objection: the 'Gazette average' is not the price of the same kind of corn at different times. It is made up from the reported sales of 'British corn' in certain markets, or on the average price of those sales, and consequently, if you compare a time when much good and little bad wheat was sold with one at which much bad was sold and little good, you will be comparing things really different. For statistical purposes such calculations may be used because they are the best which can be had, but currencies cannot be framed, or real business transacted upon them.

And, lastly, there is a fundamental fault of principle in the scheme upon which the foregoing objections more or less depend. In a good currency the paying medium ought either to be identical with, or be readily interchangeable into, a definite quantity of the standard of value. This is so, for example, so long as sovereigns are both the standard of value and the paying medium, and so long as banknotes are convertible at once for the number of sovereigns which each note mentions. But in the 'tabular plan' the 'standard' is the list of commodities in the table, and the paying medium is the gold and silver which these commodities are equal to, at variable rates, fixed from time to time. And, in consequence, the paying medium is in a state of incessant fluctuation, as compared with the standard. Sir R. Peel's question, 'What is a pound?' is answered by saying: 'The pound is a list of such and such articles;' but then none of these articles are in use; the only things in use are coins and banknotes payable in coin-so that the relation of the coinage to the 'standard' is in a state of incessant variation. And this is a fundamental fault, because the relation of the actual money to the abstract standard 
ought always to be the same, for concrete money is the only means of bringing an abstract standard into action. A good 'standard of value' is of no use without the supplement of a good paying machinery, and no such machinery can be good which shifts in its relation to the standard. This is the essential fault of an inconvertible currency, say, of 'greenbacks,' for as no one can demand metal dollars for them, they are sometimes at one value and sometimes at another. And so would the paying media under the proposed tabular system; their relation to the standard would be varied periodically, at the discretion of Commissioners, and, consequently, they would be unfit for the purposes of commerce.

We cannot think, therefore, that this plan will be of any use in practice. We must be 'Conservative,' so far as an adherence to a gold and silver coinage goes; but it is instructive to trace the effects of such schemes, and they could not be discussed unless they were proposed.

WALTER BAGEHOT 